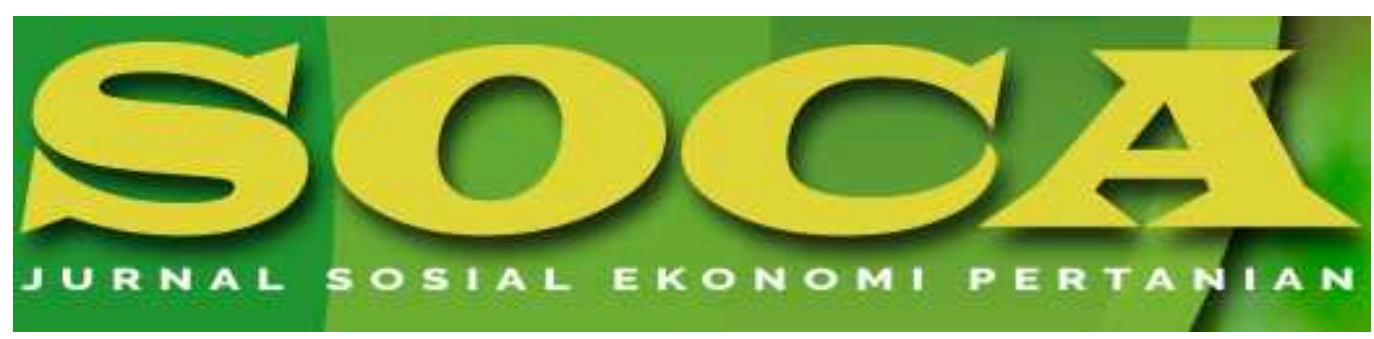

https://ojs.unud.ac.id/index.php/soca

\title{
PERAN ASOSIASI ASPAKUSA MAKMUR BOYOLALI DALAM PEMBERDAYAAN PETANI
}

\author{
Wardatul Muna, Siwi Gayatri dan Sriroso Satmoko \\ Program Studi Agribisnis, Departemen Pertanian, Fakultas Peternakan dan Pertanian, \\ Universitas Diponegoro \\ E-mail:wardamuna09@gmail.com \\ HP: 085727484419
}

\section{Kata Kunci: kemandirian, peran asosiasi, petani sayuran.}

\begin{abstract}
Abstrak
Kemampuan petani sayuran perlu ditingkatkan dengan suatu upaya sehingga dapat menghasilkan sayuran dengan kualitas dan kuantitas yang optimal guna menjawab permintaan sayuran yang semakin meningkat. Asosiasi Aspakusa Makmur Boyolali adalah asosiasi agribisnis yang berupaya meningkatkan kemadirian petani sehingga permintaan pasar terpenuhi. Penelitian ini bertujuan untuk menganalisis peran Asosiasi Aspakusa Makmur Boyolali dalam pemberdayaan terhadap kemandirian anggota. Peran asosiasi dilihat melalui indikator strategi pemberdayaan yaitu penyuluhan dan pendampingan; pengembangan sistem dan sarana pemasaran; penyediaan fasilitas pembiayaan dan permodalan; kemudahan akses IPTEK; dan penguatan kelembagaan petani. Penelitian ini dilaksanakan pada 2 Febuari - 4 Maret 2019 berlokasi di Asosiasi Aspakusa Makmur Boyolali yang terletak di Desa Teras, Kabupaten Boyolali. Metode dalam penelitian ini adalah survei dengan responden semua anggota Asosiasi Aspakusa Makmur Boyolali sebanyak 35 orang. Pengumpulan data melalui pengumpulan data primer dan sekunder. Data dianalisis melalui analisis regresi linier berganda secara analisis deskriptif kualitatif. Penelitian ini menghasilkan 1) peran Asosiasi Aspakusa Makmur Boyolali dalam pemberdayaan anggotanya dan pencapaian kemandirian anggota dikategorikan tinggi, 2) strategi pemberdayaan petani secara serempak berperan terhadap kemandirian anggota, 3) Secara parsial variabel yang mempengaruhi kemandirian anggota adalah strategi penyuluhan dan pendampingan, dan strategi kemudahan akses IPTEK.
\end{abstract}


THE ROLE OF ASPAKUSA MAKMUR BOYOLALI ASSOCIATION IN EMPOWERING FARMERS

Keywords: role
asosiation, self
relience, farmer

Keywords: role relience, farmer

\begin{abstract}
Abstrak
The vegetable farmers need an effort to increase their ability so they can produce the optimal quantiity and quality vegetables for meet an increasing demand. Aspakusa Makmur Boyolali is an agribusssines association that seeks to self farmer so that market demand can be met.This reasearch aims was to analyze the role of the Aspakusa Makmur Boyolali Association in to improve self relience anoy farmers. The role of the Association of Aspakusa Makmur Boyolali in empowerment can be seen through empowerment strategies. The research was conducted on February 2th - March 4th 2019 in Aspakusa Makmur Boyolali Association located in Teras Village, Boyolali Regency. The method used in this study was survey with 35 members of the association. Analytical methodin used descriptive analysis conducted bay multiple linear regression analysis. The results of this study were 1) the role of the Aspakusa Makmur Boyolali Association in empowering its members and self relience were categorized as high, 2) there was significant influence betwen relo of associantion in empowering strategies toward self relience anoy the farmers. 3) Partially the variables that influence self relief are counseling and mentoring strategies, and strategies for access to science and technology.
\end{abstract}

How to Cite (APA 6th Style):

Muna, W., Gayatri, S., \& Satmoko, S. (2020). Peran Asosiasi Aspakusa Makmur Boyolali dalam Pemberdayaan Petani. SOCA: Jurnal Sosial Ekonomi Pertanian, 14(1), 14-27.

https://doi.org/https://doi.org/10.24843/SOCA.2020.v14.i01.p02

\section{PENDAHULUAN}

Sayuran adalah bahan pangan yang penting karena merupakan sumber serat yang penting untuk menjaga kesehatan tubuh. Permintaan sayuran dipasaran semakin meningkat baik dari jumlahnya maupun jenis sayuran karena meningkatnya kebutuhan pangan, pertambahan jumlah penduduk, kenaikan pendapatan, berkembangnya pusat kota-industri-wisata merupakan faktor utama yang mempengaruhi peningkatan permintaan kebutuhan pangan (Saptana et al., 2016).

Kebutuhan sayuran di Indonesia yang tinggi dan terus meningkat mendorong para petani untuk dapat menghasilkan tanaman sayuran dengan kualitas serta kuantitas yang optimal. Berdasarkan hal tersebut maka diperlukan suatu upaya yang dapat meningkatkan kemampuan petani guna menjawab tantangan tersebut.

Pemberdayaan masyarakat adalah upaya mengajak masyarakat menyelesaikan masalah dan meningkatkan kemampuan dalam mengambil keputusan bersama-sama yang dapat mempengaruhi dan meningkatkan kualitas 
hidup (Sopyan, 2014). Pemberdayaan merupakan upaya yang penting guna meningkatkan posisi petani (Sumarna, 2012). Oleh karena itu, pemberdayaan petani sayur perlu dilakukan guna meningkatkan posisi petani untuk menyelesaikan masalah melalui potensi dan kemampuan yang dimiliki secara mandiri.

Upaya pemberdayaan petani guna meningkatkan produktivitas, pendapatan dam kesejateraan dapat dilakukan oleh kelembagaan pertanian seperti kelompok tani (Darajat, 2011) dalam Nuryanti, 2011). Hasil penelitian Mario (2017) menyatakan salah satu tujuan yang ingin dicapain masyrakat petani dengan bergabung dalam suatu kelembagaan adalah memperbaiki kesejahteraan hidupnya agar mampu menjadi petani yang mandiri dan berdaya saing serta mampu mengangkat derajat keluarganya.

Mr. Lee Ching Shui selaku pimpinan Taiwan Technical Mission (TTM) memprakarsai berdirinya Asosiasi Aspakusa Makmur Boyolali sebagai kelembagaan agribisnis yang bergerak dalam usaha komoditas sayuran. Sejak berdiri pada 10 November 2005 telah bekerjasama dengan petani mitra, petani anggota, serta mitra pemasaran yang tersebar di Pulau Jawa. Hingga saat ini Asosiasi Aspakusa Makmur Boyolali telah beranggota 35 petani yang tersebar di dataran rendah dan dataran tinggi Kabupaten Boyolali yang berusahatani berbagai jenis sayuran.

Asosiasi Aspakusa Makmur Boyolali terus berupaya mengembangkan pertanian sayuran melalui berbagai kegiatan seperti pembudidayaan tanaman, penanganan pasca panen dan pemasaran guna memenuhi permintaan pasar. Berdasarkan hal tersebut dapat dikatakan bahwa Asosiasi Aspakusa Makmur Boyolali adalah salah satu kelembagaan pertanian yang berupaya untuk pemberdayaan masyarakat petani.

Menurut hasil penelitian Nuryanti (2011) peran kelembagaan pertanian sesuai dengan kelompok tani yang berfungsi sebagai forum belajar, unit produksi dan wahana kerjasama. Hasil penelitian Nugroh \& Rahayu (2014) menyatakan bahwa kelembagaan pertanian berperan dalam pemberdayaan petani dengan memudahkan anggotanya untuk memperoleh modal produksi baik berupa uang maupun sarana prasarana.

Berdasarkan penelitian terdahulu yang dilakukan oleh Hakim \& Sugihen (2007) menemukan bahwa peran kelembagaan pertanian guna meningkatkan keberdayaan petani dalam meningkatkan produktivitas dan pendapatannya dipengaruhi oleh kemampuan mengembangkan tingkat kepribadian, lingkungan sosial, pola pemberdayaan dan akses pada informasi. Hal ini juga diperkuat oleh Kusumawati (2017) menemukan bahwa suatu kelembagaan pertanian dapat berhasil berperan komunikasi yang baik dengan melalui pertemuan rutin seperti kegiatan pembelajaran, penyuluhan, pelatihan, pembinaan, dan pendampingan sehingga dapat menyusun dan menyelesaikan permasalahan masyarakat.

Penelitian ini bertujuan untuk mendeskripsikan peran Asosiasi Aspakusa Makmur Boyolali dalam pemberdayaan anggota Asosiasi Aspakusa Makmur Boyolali, serta menganalisis peran Asosiasi Aspakusa Makmur Boyolali terhadap pemberdayaan anggota Asosiasi Aspakusa Makmur Boyolali melalui strategi pemberdayaan petani dalam Undang-Undang Pemberdayaan dan Penyuluhan Petani No. 19 tahun 2013. Pentingnya peran kelembagaan diambil dari model strategi pemberdayaan (Hakim \& Sugihen, 2007). Penelitian ini penting dilakukan agar kelembagaan pertanian seperti asosiasi, kelompok tani dan yang lainnya dapat 
mempertimbangkan setrategi pemberdayaan yang baik guna mencapai kemandirian anggotanya.

\section{METODE PENELITIAN}

Penelitian ini dilaksakan pada bulan 2 Febuari - 4 Maret 2019 di Asosiasi Aspakusa Makmur Boyolali yang terletak di Dukuh Banjarsari, Desa Teras, Kecamatan Teras, Kabupaten Boyolali.

Penelitian ini menggunakan metode survei yaitu dengan melakukan wawancara langsung kepada anggota Asosiasi Aspakusa Makmur Boyolali menggunakan kuesioner. Penentuan sampel dengan complete enumeration yaitu mengambil semua anggota Asosiasi Aspakusa Makmur Boyolali sebagai responden sebanyak 35 orang.

Data penelitian ini dikumpulkan dengan dua cara yaitu data primer dan sekunder dengan wawancara, observasi dan dokumentasi. Data primer didapat dari hasil wawancara dengan anggota Asosiasi Aspakusa Makmur Boyolali bedasarkan kuesioner yang telah dipersiapkan untuk mendapatkan informasi yang berkaitan dengan peran Asosiasi Aspakusa Makmur Boyolali dalam pemberdayaan anggotanya. Pengukuran peran asosiasi dan pemberdayaan menggunakan skala likert yang dilengkapi 5 alternatif jawaban yaitu : (1) sangat tidak setuju, (2) tidak setuju, (3) netral, (4) setuju, dan (5) sangat setuju. Data sekunder didapat dari jurnal terkait, buku, serta instansi atau pihak-pihak yang berhubungan dengan Asosiasi Aspakusa Makmur Boyolali. Data selanjutnya dianalisis dengan model regresi linier berganda menggunakan persamaan regresi linear berganda di bawah ini (Ghozali, 2011) :

$\mathrm{Y}=\mathrm{a}+\mathrm{b}_{1} \mathrm{X}_{1}+\mathrm{b}_{2} \mathrm{X}_{2}+\mathrm{b}_{3} \mathrm{X}_{3}+\mathrm{b}_{4} \mathrm{X}_{4}+\mathrm{b}_{5} \mathrm{X}_{5}+\mathrm{e}$

Keterangan :

$\mathrm{Y} \quad$ : Kemandirian anggota Asosiasi Aspakusa Makmur Boyolali (skor)

a : Nilai konstanta

b : Nilai koefisien regresi

e : Error

$\mathrm{X}_{1}$ : penyuluhan dan pendampingan (skor)

$\mathrm{X}_{2} \quad$ : pengembangan sistem dan sarana pemasaran hasil pertanian (skor)

$\mathrm{X}_{3} \quad$ : penyediaan fasilitas pembiayaan dan permodalan (skor)

$\mathrm{X}_{4} \quad$ : kemudahan akses ilmu pengetahuan, teknologi dan informasi (skor)

$\mathrm{X}_{5} \quad$ : penguatan kelembagaan petani (skor)

Kriteria pengujian

1. $\mathrm{H}_{0}: \mathrm{b}=0$, artinya antara variabel strategi pemberdayaan oleh Asosiasi Aspakusa Makmur Boyolali tidak berpengaruh secara parsial dan serempak terhadap variabel kemandirian anggota

2. $\mathrm{H}_{1}: \mathrm{b} \neq 0$, artinya antara variabel strategi pemberdayaan oleh Asosiasi Aspakusa Makmur Boyolali berpengaruh secara parsial dan serempak terhadap variabel kemandirian anggota

Pengambilan Keputuasan

1. Nilai siginfikasi $>0,05$ maka $\mathrm{H}_{0}$ diterima, $\mathrm{H}_{1}$ ditolak artinya variabel strategi pemberdayaan tidak berpengaruh terhadap kemandirian anggota. 
2. Nilai siginfikasi $\leq 0,05$ maka $\mathrm{H}_{0}$ ditolak, $\mathrm{H}_{1}$ diterima artinya variabel strategi pemberdayaan berpengaruh terhadap kemandirian anggota.

\section{HASIL DAN PEMBAHASAN}

Asosiasi Aspakusa Makmur Boyolali merupakan asosiasi petani yang berhasil dan terus berkembang secara berkelanjutan, sejak didirikan pada 10 November 2005 atas prakarsa pimpinan Taiwan Technical Mission (TTM). Asosiasi Aspakusa Makmur Boyolali beranggotakan 35 petani yang tersebar di Kabupaten Boyolali, serta bermitra dengan 22 supermarket yang tersebar di 4 kota. Produk utamanya adalah sayuran segar yang dibudidayakan di dataran rendah dan dataran tinggi. Asosiasi Aspakusa Makmur Boyolali memiliki visi meningkatkan kesejahteraan petani dan misi meningkatkan pengetahuan petani, meningkatkan kualitas produk sayuran hortikultur dan memperluas pangsa pasar.

Pengurus asosiasi ini dipilih berdasarkan kesepakatan seluruh anggota asosiasi, bertanggung jawab atas kinerja Aspakusa Makmur. Bagan kepengurusan Asosiasi Aspakusa Makmur Boyolali. Asosiasi Aspakusa Makmur Boyolali berada dibawah binaan Dinas Pertanian Jawa Tengah, Dinas Ketahanan Pangan Propinsi Jawa Tengah, Dinas Pertanian Kabupaten Boyolali dan Dinas Ketahanan Pangan Kabupaten Boyolali. Tahapan produksi di Asosiasi Aspakusa Makmur Boyolali dimulai dari budidaya tanaman oleh petani dan pihak yang berkerjasama di lahannya masing-masing serta budidaya dilahan Asosiasi Aspakusa Makmur Boyolali yang dikerjakan oleh 3 pekerja lahan, pemanenan, sortasi, pencucian, penyimpanan, packing, dan pengiriman.

\section{Karakteristik Responden}

Karakteristik responden berdasarkan jenis kelamin adalah 74,29\% anggota Asosiasi Aspakusa Makmur Boyolali adalah laki-laki dan 25,71\% adalah perempuan. Hal ini berbanding dengan jumlah penduduk di Kabupaten Boyolali yang mana jumlah penduduk wanita yaitu 494.787 jiwa lebih banyak dibanding penduduk laki-laki 479.792 jiwa. Jumlah anggota Asosiasi Aspakusa Makmur Boyolali yang didominasi laki-laki ini sesuai dengan pendapat (Elizabeth, 2007) yang menyatakan bahwa secara produktifitas bekerja mendukung kaum laki-laki sebagai kepala keluarga untuk mencari penghasilan. Tabel 1 menunjukan bahwa sebagian besar responden berusia produktif (15-44 tahun) dan 34,29\% responden sudah diatas usia prodiktif yaitu lebih dari 50 tahun.

Tabel 1. Jumlah dan Prosentase Berdasarkan Karekteristik Anggota Asosiasi Aspakusa Makmur Boyolali ( $\mathrm{N}=35)$

\begin{tabular}{ccccc}
\hline No & Karakteristik & Kategori & Jumlah & Persentase \\
\hline \multirow{2}{*}{1.} & \multirow{3}{*}{ Jenis Kelamin } & Laki-Laki & ---orang--- & $------(\%)-----$ \\
& & Perempuan & 9 & 74,29 \\
& Usia (Tahun) & 20 sd 30 & 3 & 25,71 \\
\hline 2. & 31 sd 40 & 5 & 8,57 \\
& & 41 sd 50 & 15 & 14,29 \\
& & &
\end{tabular}




\begin{tabular}{|c|c|c|c|c|}
\hline & & $>50$ & 12 & 34,29 \\
\hline \multirow[t]{4}{*}{3.} & Tingkat & $\mathrm{SD}$ & 5 & 14,29 \\
\hline & Pendidikan & SMP & 6 & 17,14 \\
\hline & & SMA & 20 & 57,14 \\
\hline & & Perguruan Tinggi & 4 & 11,43 \\
\hline \multirow[t]{4}{*}{4.} & Alamat & Teras & 25 & 71,43 \\
\hline & & Selo & 5 & 14,29 \\
\hline & & Boyolali & 2 & 5,71 \\
\hline & & Ampel & 3 & 8,57 \\
\hline \multirow[t]{4}{*}{5.} & Pengalaman & $<10$ & 8 & 22,86 \\
\hline & bertani & $10-19$ & 13 & 37,14 \\
\hline & (Tahun) & $20-30$ & 10 & 28,57 \\
\hline & & $>30$ & 4 & 11,43 \\
\hline \multirow[t]{4}{*}{6.} & lama & $<6$ & 8 & 22,86 \\
\hline & bekerjasama & $6-10$ & 10 & 28,57 \\
\hline & $\begin{array}{c}\text { dengan Assosiasi } \\
\text { (Tahun) }\end{array}$ & $11-15$ & 12 & 34,29 \\
\hline & & $>15$ & 5 & 14,29 \\
\hline \multirow[t]{4}{*}{7.} & luas lahan & $<600$ & 8 & 22,86 \\
\hline & $\left(\mathrm{M}^{2}\right)$ & $600-1000$ & 4 & 11,43 \\
\hline & & $1001-2000$ & 10 & 28,57 \\
\hline & & $>2000$ & 13 & 37,14 \\
\hline \multirow[t]{3}{*}{8.} & status lahan & milik sendiri & 28 & 80,00 \\
\hline & & Sewa & 5 & 14,29 \\
\hline & & $\begin{array}{l}\text { miliksendiri }+ \\
\text { sewa }\end{array}$ & 2 & 5,71 \\
\hline
\end{tabular}

Sumber : Data primer penelitian yang diolah, 2019

Menurut Prasetyo (2013) keikutsertaan petani yang berusia sudah tua menunjukan keingginannya mengikuti kemitraan untuk mengembangkan usahatani sayurannya dengan. Hal tersebut dapat memotivasi petani muda untuk terus mengembangkan usahanya lebih keras lagi.

Berdasarkan hasil penelitian menunjukan bahwa Pendidikan responden mayoritas adalah STLA dengan persentase 57,14\%. Menurut Sarwono (2010) dalam Prasetyo (2013), harapan mempengaruhi persepsi seseorang, sedangkan tingkat latar belakang pendidikan seseorang akan berpengaruh terhadap harapannya. Tingkat pendidikan petani inilah yang membuat petani memiliki kemampuan dan keinginan guna mengembangkan usahataninya dengan salah satu caranya menjadi anggota Asosiasi Aspakusa Makmur. Sebanyak 71,43\% adalah anggota yang beralamat di Kecamatan Teras. Hal ini dilandasi oleh harapan Asosiasi mampu bermanfaat utamanya bagi masyarakat di sekitarnya. 
Tabel 2. Jumlah dan Persentase Responden Berdasarkan Peran Asosiasi Aspakusa Makmur Boyolali dalam Melaksakan Pemberdayaan

\begin{tabular}{ccccc}
\hline No & Kategori & Nilai & Jumlah & Persentase \\
\hline & & & --- Orang--- & $----\%----$ \\
1 & Tinggi & $\geq 92$ & 35 & 100 \\
2 & Sedang & $58 \mathrm{~s} / \mathrm{d} 91$ & 0 & 0 \\
3 & Rendah & $<58$ & 0 & 0 \\
\hline & & Jumlah & 35 & 100
\end{tabular}

Sumber : Data primer penelitian yang diolah, 2019

Responden yang memiliki pengalaman bertani dibawah 10 tahun dan bekerjasama dibawah 6 tahun berjumlah 8 orang atau 22,86\% (Tabel 1). Pengalaman dalam bertani dan berkerjasama mempengaruhi persepsi petani terhadap peran asosiasi, karena petani mengambil keputusan sesuai pengalaman dan mampu mengefisienkan manajemen usaha taninya (Sumarna, 2012).

Berdasarkan penelitian yang telah dilakukan diketahui luas lahan usaha anggota Asosiasi Aspakusa Makmur sebanyak 37,14\% lebih dari $2000 \mathrm{~m} 2$, sedangkan anggota yang memiliki luas lahan kurang dari 600-1000 m2 terdapat $34,29 \%$. Sebagian besar lahan usaha responden merupakan lahan milik sendiri yaitu sebesar $80 \%$. Luas lahan dan status kepemilikan lahan berpengaruh terhadap pendapatan petani. Semakin luas lahan maka pendapatan akan meningkat karena jumlah produksi yang semakin tinggi. Status kepemilikan lahan berpengaruh pada pendapatan karena biaya sewa lahan.

\section{Peran Asosiasi Aspakusa Makmur Boyolali dalam melaksanakan Pemberdayaan}

Berdasarkan hasil analisis data yang dapat dilihat pada tabel 2 Asosiasi Aspakusa Makmur Boyolali dalam melaksanakan pemberdayaan berperan tinggi dengan rata-rata skor sebesar 104,1. Hal ini menunjukan persepsi responden terhadap peran Asosasi Aspaakusa dalam melaksanakan strategi pemberdayaan (X) telah baik, dikarenakan setiap anggota dapat bergabung atau berpartisipasi dalam peran yang dilaksanakan. Hasil penelitian ini sejalan dengan hasil penelitian oleh Hakim \& Sugihen (2007) yang menyatakan bahwa peran suatu kelembagaan dalam pemberdayaan dapat dilihat dari produktivitas kerja petani yang memerlukan adanya penguatan inisiatif dan partisipasi anggotanya.

Peran Asosiasi Aspakusa Makmur Boyolali dalam melaksakan pemberdayaan dilihat dari strategi pemberdayaan yang dilakukan yaitu penyuluhan dan pendampingan; pengembangan sistem dan sarana pemasaran; penyediaan fasilitas pembiayaan dan permodalan; kemudahan akses ilmu pengetahuan, teknologi dan informasi; serta penguatan kelembagaan petani. Anggota juga merasakan dengan kegiatan ini dapat meningkatkan pendapatan. Pengurus Asosiasi Aspakusa diharapkan dapat mempertahankan dan meningkatkan partisipasi anggota dalam kegiatan pemberdayaan. 
Tabel 3. Jumlah dan Persentase Responden Berdasarkan Peran Asosiasi Aspakusa Makmur Boyolali dalam Strategi Penyuluhan dan Pendampingan

\begin{tabular}{ccccc}
\hline No & Kategori & Nilai & Jumlah & Persentase \\
\hline & & & --- Orang--- & $----\%----$ \\
1 & Tinggi & $\geq 18$ & 35 & 100 \\
2 & Sedang & $12 \mathrm{~s} / \mathrm{d} 17$ & 0 & 0 \\
3 & Rendah & $<12$ & 0 & 0 \\
\hline & & Jumlah & 35 & 100 \\
\hline
\end{tabular}

Sumber : Data primer penelitian yang diolah, 2019

\section{Penyuluhan \& Pendampingan $\left(\mathbf{X}_{1}\right)$}

Berdasarkan tabel 3 diketahui jawaban responden terhadap peran Asosiasi Aspakusa Makmur Boyolali dalam kegiatan penyuluhan dan pendampingan dikategorikan tinggi dan rata-rata skor jawaban sebesar 21,1143. Hal ini berarti peran asosiasi dalam strategi penyuluhan dan pemberdayaan yang meliputi mengalisis situasi, meningkatkan dan pegembangkan usahatani, penyebarluasan informasi dan teknologi pertanian, serta pemecahan masalah telah berperan baik. Menurut Mangowal (2013) kegiatan penyuluhan membantu petani meningkatkan pengetahuan sehingga usahataninya berkembang.

Tabel 4. Jumlah dan Persentase Responden Berdasarkan Peran Asosiasi Aspakusa Makmur Boyolali dalam Strategi Pengembangan Sistem dan Sarana Pemasaran Hasil Pertanian

\begin{tabular}{cccc}
\hline Kategori & Nilai & Jumlah & Persentase \\
\hline Tinggi & $\geq 18$ & ---Orang--- & $----\%^{----}$ \\
Sedang & $12 \mathrm{~s} / \mathrm{d} 17$ & 34 & 97 \\
Rendah & $<12$ & 0 & 3 \\
\hline & Jumlah & 35 & 0 \\
\hline
\end{tabular}

Sumber : Data primer penelitian yang diolah, 2019

\section{Pengembangan Sistem dan Sarana Pemasaran Hasil Pertanian $\left(\mathbf{X}_{2}\right)$}

Berdasarkan tabel 4, jawaban responden terhadap peran Asosiasi Aspakusa Makmur Boyolali dalam strategi pengembangan sistem dan sarana pemasaran hasil pertanian memiliki kategori tinggi atau berperan baik sebesar $97 \%$ dan rata-rata skor jawaban sebesar 20,3429. Pemberdaayan masyarakat petani yang berorientasi agribisnis dengan memperhatikan selera pasar dan kepuasan konsumen, sehingga mampu mengoptimalkan produksi dan meningkatkan daya saing (Taufik, 2012). Asosiasi Aspakusa Makmur Boyolali yang memiliki visi meningkatkan kualitas produk sayuran dan memperluas pangsa pasar telah mewujudkannya melalui berbagai kegiatan. Kegiatan yang dilakukan dalam strategi pengembangan sistem dan sarana pemasaran sesuai dengan strategi pemberdayaan (UU nomor 19 Tahun 2013), yaitu melalui mewujudkan pasar hasil pertanian yang memiliki standar, mewujudkan terminal dan sub terminal agribisnis, mendukung fasilitas pemasaran, serta menyediakan informasi pasar. 
Tabel 5. Jumlah dan Persentase Responden berdasarkan Peran Asosiasi Aspakusa Makmur Boyolali dalam Strategi Penyediaan Fasilitas Pembiayaan dan Permodalan

\begin{tabular}{ccccc}
\hline No & Kategori & Nilai & Jumlah & Persentase (\%) \\
\hline & & & --- Orang--- & ---- \%---- \\
1 & Tinggi & $\geq 18$ & 35 & 100 \\
2 & Sedang & $12 \mathrm{~s} / \mathrm{d} 17$ & 0 & 0 \\
3 & Rendah & $<12$ & 0 & 0 \\
\hline & & $\geq 18$ & 35 & 100 \\
\hline
\end{tabular}

Sumber : Data primer penelitian yang diolah, 2019

\section{Penyediaan Fasilitas Pembiayaan dan Permodalan $\left(\mathbf{X}_{3}\right)$}

Berdasarkan tabel 5 menunjukan persepsi responden Asosiasi Aspakusa Makmur Boyolali telah berperan baik dalam menjalankan strategi penyediaan fasilitas pembiayaan dan permodalan dengan kategori tinggi sebesar 100\% dan ratarata skor jawaban sebesar 20,4. Sugiarti \& Ma'ruf (2016) yang menyatakan bahwa permasalahan pada pertanian di Indonesia salah satunya adalah aspek permodalan karena sulitnya mendapatkan bantuan modal. Oleh karenanya Asosiasi Aspakusa Makmur dengan visinya meningkatkan kesejahteraan petani, memfasilitasi pembiayaan dan permodalan melalui penguatan modal bagi petani dan pengembangan sumber daya manusia. Hal ini sesuai dengan pendapat Martati et al. (2013) yang menyatakan bahwa petani juga memerlukan bantuan dana dari masa tanam hingga masa panen serta kebijakkan saprodi yang dapat membantu petani dalam meningkatkan produktifitas hasil pertanian.

\section{Kemudahan Akses Ilmu Pengetahuan, Teknologi dan Informasi $\left(\mathrm{X}_{\mathbf{4}}\right)$}

Berdasarkan tabel 6 menunjukan bahwa menurut persepsi responden, Aspakusa Makmur telah berperan baik dalam menjalankan strategi kemudahan akses IPTEK dengan kategori jawaban tinggi sebesar $100 \%$ dan rata-rata skor jawaban sebesar 21,37. Pemberdayaan dapat menjamin jumlah, kualitas dan kuantitas produknya, melalui peningkatan penerapan teknologi pembibitan, budidaya, panen dan pasca panen (Saptana et al., 2016). Asosiasi Aspakusa Makmur sebagai kelembagaan pertanian telah membantu pemerintah dalam memberikan kemudahan akses ilmu pengetahuan teknologi dan informasi kepada petani untuk mencapai standar mutu komoditas pertanian melalui misinya untuk meningkatkan pengetahuan petani, meningkatkan kualitas produk sayuran, serta memperluas pasar.

Tabel 6. Jumlah dan Persentase Responden berdasarkan Peran Asosiasi Aspakusa Makmur dalam Strategi Kemudahan Akses Ilmu Pengetahuan, Teknologi dan Informasi

\begin{tabular}{ccccc}
\hline No & Kategori & Nilai & Jumlah & Persentase \\
\hline & & & ---Orang-- & ----\%---- \\
1 & Tinggi & $\geq 18$ & 35 & 100 \\
2 & Sedang & $12 \mathrm{~s} / \mathrm{d} 17$ & 0 & 0 \\
3 & Rendah & $<12$ & 0 & 0 \\
\hline
\end{tabular}




\begin{tabular}{lll}
\hline Jumlah & 35 & $100 \%$ \\
\hline
\end{tabular}

Sumber : Data primer penelitian yang diolah, 2019

\section{Penguatan Kelembagaan Pertanian (X5)}

Berdasarkan tabel 7 menunjukan bahwa menurut persepsi responden Asosiasi Aspakusa Makmur Boyolali telah berperan baik dalam menjalankan strategi penguatan kelembagaan petani dengan kategori tinggi sebesar $100 \%$ dan rata-rata skor jawaban sebesar 20,8286. Asosiasi Aspakusa Makmur Boyolali sebagai kelembagaan pertanian telah membantu pemerintah dalam penguatan kelembagaan pertanian, dengan menjalankan program-program yang berkelanjutan guna meningkatkan produktivitas petani. Hal ini sesuai dengan Undang-Undang Nomor 19 Tahun 2013 Pasal 69 yang menyatakan bahwa pemerintah memiliki kewajiban untuk mendorong dan memfasilitasi terbentuknya kelembagaan ekonomi dan kelembagaan petani. Menurut (Elizabeth, 2007) penguatan kelembagaan diharapkan mampu menghasilkan kesinambungan dan keberlanjutan daya dukung sumber daya alam dan berbagai usaha dalam menunjang aktivitas pembangunan, serta dapat melindungi bargaining position petani.

Tabel 7. Jumlah dan Presentase Responden berdasarkan Peran Asosiasi Aspakusa Makmur Boyolali dalam Strategi Penguatan Kelembagaan Petani

\begin{tabular}{ccccc}
\hline No & Kategori & Nilai & Jumlah & Persentase (\%) \\
\hline & & & ---Orang--- & ----\%---- \\
\hline 1 & Tinggi & $\geq 18$ & 35 & 100 \\
2 & Sedang & 12 s/d 17 & 0 & 0 \\
3 & Rendah & $<12$ & 0 & 0 \\
\hline & & Jumlah & 35 & 100 \\
\hline
\end{tabular}

Sumber : Data primer penelitian yang diolah, 2019

\section{Persepsi Petani terhadap Kemandirian Anggota (Y)}

Berdasarkan tabel 8 menunjukan bahwa Asosiasi Aspakusa Makmur Boyolali berperan baik dalam pemberdayaan sehingga anggotanya dapat mandiri dengan kategori tinggi sebesar $100 \%$ dengan rata-rata skor jawaban sebesar 42,6176. Petani merasa dengan bergabung sebagai anggota Asosiasi Aspakusa mampu meningkatkan kemandiriaanya, sehingga petani dapat mengembangkan produksi usahtani, melihat potensi pasar serta mampu menyelesaikan masalahnya. Kemandirian petani dapat dilihat dari kemampuan pemilihan jenis komoditas yang ditanam; penanganan hasil panen; serta pemasaran (Farid, 2008).

Tabel 8. Jumlah dan Presentase Responden berdasarkan Kemandirian Anggota

\begin{tabular}{ccccc}
\hline No & Kategori & Nilai & Jumlah & Persentase (\%) \\
\hline & & & --- Orang--- & $----\%$---- $^{-}$ \\
\hline 1 & Tinggi & $\geq 32$ & 35 & 100 \\
2 & Sedang & 18 s $/ \mathrm{d} \mathrm{31}$ & 0 & 0 \\
3 & Rendah & $<18$ & 0 & 0 \\
\hline
\end{tabular}




\begin{tabular}{lll}
\hline Jumlah & 35 & 100 \\
\hline
\end{tabular}

Sumber : Data primer penelitian yang diolah, 2019

\section{Hasil Uji Analisis Peran Asosiasi Aspakusa Makmur Boyolali dalam Pemberdayaan Petani}

Berdasrkan hasil uji f melalui SPSS 16.0 yang menunjukan bahwa nilai sig $0,00 \leq 0,05$ dan $\mathrm{f}$ hitung sebesar 29,401 > f tabel 2,69 $(\mathrm{N}=35)$ yang berarti $\mathrm{H}_{0}$ ditolak dan $\mathrm{H}_{1}$ diterima. Hal ini menunjukan bahwa variabel strategi pemberdayaan berpengaruh yang serempak terhadap varibel kemandirian anggota. Strategi pemberdayaan yang dilakukan Asosiasi Aspakusa Makmur Boyolali mencakup kegiatan agribisnis. Menurut (Mangowal, 2013) pemberdayaan petani perlu dilakukan dengan pentingnya agribisnis yang mencakup on-fram, industri hilir, dan pemasaran produk.

Berdasarkan uji Koefisien Determinasi R² melalui SPSS 16.0 diperoleh hasil bahwa besarnya pengaruh variabel strategi terhadap variabel pencapaian kemandirian anggota dilihat dari pada nilai Adjusted R Square sebesar 80,7\% dan sisanya dipengaruhi oleh variabel lain. Hal ini sesuai pendapat (Ghozali, 2011) yang menyatakan bahwa koefisien determinasi $\left(\mathrm{R}^{2}\right)$ digunakan untuk mengukur seberapa jauh kemampuan variabel independen dalam menerangkan variabel dependen.

Peran Asosiasi Aspakusa Makmur dalam pengembangan sistem dan sarana pemasaran hasil pertanian $\left(\mathrm{x}_{2}\right)$, penyediaan fasilitas pembiayaan dan permodalan $\left(\mathrm{X}_{3}\right)$ dan penguatan kelembagaan petani $\left(\mathrm{X}_{5}\right)$ memiliki nilai signifikasi $>0,05$ dan nilai $\mathrm{t} \leq \mathrm{t}$ tabel 2,03452 berarti hanya strategi penyuluhan dan pendampingan $\left(\mathrm{x}_{1}\right)$ dan kemudahan akses ilmu pengetahuan, teknologi dan informasi ( $\left.\mathrm{x}_{4}\right)$ yang berpengaruh secara parsial terhadap pencapaian kemandirian anggota. Hal ini sejalann dengan hasil penelitian Farid (2008) yang menyatakan bahwa kemadirian petani sangat dipengaruhi oleh akses informasi. Peran Asosiasi Aspakusa Makmur sebagai kelembagaan pertanian didukung juga oleh penelitian Nuryanti (2011) yang menyatkan bahwa peran kelembagaan pertanian adalah sebagai forum belajar, wahana kerjasama dan unit produksi. Berdasarkan hasil uji SPSS 16.0 diperoleh persamaan regresi linier berganda yaitu:

$$
\mathrm{Y}=5,528+0,409 \cdot \mathrm{X}_{1}+0,291 \cdot \mathrm{X}_{2}-0,156 \cdot \mathrm{X}_{3}+1,310 \cdot \mathrm{X}_{4}-0,159 \cdot \mathrm{X} 5
$$

Hal ini berarti jika tidak ada nilai skor penyuluhan dan pendampingan $\left(\mathrm{X}_{1}\right)$; pengembangan sistem dan sarana pemasaran hasil pertanian $\left(\mathrm{X}_{2}\right)$; penyediaan fasilitas pembiayaan dan permodalan $\left(\mathrm{X}_{3}\right)$; kemudahan akses ilmu pengetahuan, teknologi dan informasi $\left(\mathrm{X}_{4}\right)$; dan penguatan kelembagaan petani $\left(\mathrm{X}_{5}\right)$ maka pencapaian kemandirian anggota akan sama dengan 5,528.

Peran peyuluhan oleh Asosiasi Aspakusa Makmur Boyolali dalam mencapai kemandirian anggota berpengaruh positif secara signifikan, dengan persamaan regrsi setiap penambahan satu skor strategi pemberdayaan penyuluhan dan pendampingan $\left(\mathrm{X}_{1}\right)$, maka skor pencapaian kemandirian anggota meningkat sebesar 0,409 . Peran penyuluhan sangat penting untuk menambah pengetahuan serta pendampingan kepada petani sehingga dapat mencapai kemandirian anggota. 
Tabel 9. Hasil Uji T

\begin{tabular}{|c|c|c|c|c|}
\hline \multirow{2}{*}{ Model } & \multicolumn{2}{|c|}{ Unstandardized } & \multirow{2}{*}{$\mathrm{T}$} & \multirow{2}{*}{ Sig. } \\
\hline & B & Std. Error & & \\
\hline (Constant) & 5.528 & 3.904 & 1.416 & .167 \\
\hline Penyuluhan \& pendampingan (x1) & .409 & .176 & 2.323 & .027 \\
\hline Sistem dan sarana pemasaran (x2) & .291 & .147 & 1.974 & .058 \\
\hline Pembiayaan dan permodalan (x3) & -.156 & .203 & -.765 & .451 \\
\hline Akses IPTEK (x4) & 1.310 & .173 & 7.572 & .000 \\
\hline Penguatan kelembagaan (x5) & -.109 & .213 & -.511 & .613 \\
\hline
\end{tabular}

Sumber : Data primer penelitian yang diolah, 2019

Berdasarkan hasil analisis diketahui setiap penambahan satu skor strategi pengembangan sistem dan sarana pemasaran hasil pertanian $\left(\mathrm{X}_{2}\right)$, maka skor pencapaian kemandirian anggota meningkat sebesar 0,291. Strategi pengembangan sistem dan sarana pemasaran hasil pertanian tidak perpengaruh secara signifikan terhadap pencapaian kemadirian, petani dalam proses penyetotan ke Aspakusa masih mengalami kendala sarana pengiriman yang ditanggung sendiri oleh petani.

Setiap penambahan satu skor strategi penyediaan fasilitas pembiayaan dan permodalan $\left(\mathrm{X}_{3}\right)$, maka skor pencapaian kemandirian anggota penurunan sebesar 0,156 . Strategi penyediaan fasilitas pembiayaan dan permodalan tidak perpengaruh secara signifikan untuk mencapai kemandirian anggota. Hal ini dikarenakan Aspakusa hanya menyediakan bibit/biji tanaman tertentu, serta belum membantu menyediakan berbagi sarana produksi. Hal ini seuai dengan pendapat (Rifa, 2013) yang menyatakan bahwa perkuatan dalam pemberdayaan menyangkut penyediaan berbagi masukan.

Setiap penambahan satu skor strategi kemudahan akses ilmu pengetahuan, teknologi dan informasi $\left(\mathrm{X}_{4}\right)$, maka skor pencapaian kemandirian anggota meningkat sebesar 1,310. Strategi kemudahan akses ilmu pengetahuan, teknologi dan informasi secara parsial perpengaruh signifikan terhadap pencapaian kemandirian anggota, kerana kemudahan akses IPTEK sangat membantu petani untuk memperkuat pengetahuan dan kemampuan yang dimiliki.

Strategi penguatan kelembagaan petani secara parsial tidak berpengaruh signifikan, tetapi perpengaruh positif dengan setiap penambahan satu skor strategi penguatan kelembagaan petani $\left(\mathrm{X}_{5}\right)$, maka skor pencapaian kemandirian anggota menurun sebesar -0,109. Asosiasi Aspakusa tidak melakukan pertemuan rutin, masalah yang ada dimusyawarahkan dengan sebagian anggota, pengurus dan staf. Pertemuan rutin sangat penting guna meningkatkan kohevisitas suatu kelompok. Menurut (Putranto, 2012) tingginya tingkat kohesivitas bermanfaat untuk memaksimalkan fungsi kelompok, karena keeksisan anggota kelompok akan tetap terjaga. 


\section{KESIMPULAN DAN SARAN}

\section{Simpulan}

Berdasarkan hasil penelitian dapat disimpulkan bahwa peran Asosiasi Aspakusa Makmur Boyolali dalam pemberdayaan anggotanya dan pencapaian kemandirian anggota berperan sangat baik dan dikategorikan tinggi. Peran Asosiasi Aspakusa Makmur Boyolali dalam pemberdayaan anggotanya melalui strategi pemberdayaan petani secara serempak berperan terhadap pencapaian kemandirian anggota. Secara parsial variabel yang mempengaruhi pencapaian kemandirian anggota adalah strategi penyuluhan dan pendampingan, serta strategi kemudahan akses ilmu pengetahuan, teknologi dan informasi; sedangkan strategi pengembangan sistem dan sarana pemasaran hasil pertanian, penyediaan fasilitas pembiayaan dan permodalan, serta penguatan kelembagaan petani tidak perpengaruh secara parsial.

\section{Saran}

Diharapkan terdapat sosialisasi dan pendampingan secara berkala baik dari pemerintah, akademik maupun swasta kepada anggota Asosiasi Aspakusa Makmur Boyolali guna menjalankan strategi penyediaan fasilitas pembiayaan dan permodalan sehingga dapat mem bantu dalam menjalankan usahatani sayuran agar dapat lebih efisien. Serta diharapkan Asosiasi Aspakusa Makmur Boyolali lebih sering mengadakan pertemuan rutin untuk meningkatkan kohevisitas kelompok.

\section{DAFTAR PUSTAKA}

Elizabeth, R. (2007). Penguatan dan Pemberdayaan Kelembagaan Petani Mendukung Pengembangan Agribisnis Kedelai. Agribisnis Kedelai. Pusat Analisis Sosial Ekonomi Dan Kebijakan Pertanian, Bogor, 165-173.

Farid, A. (2008). Kemandirian Petani dalam Pengambilan Keputusan Usahatani: Kasus Petani Sayuran di Kabupaten Bondowoso dan Kabupaten Pasuruan. Disertasi, IPB.

Ghozali, I. (2011). Aplikasi Analisis Multivariate dengan Program SPSS. Universita.

Hakim, L., \& Sugihen, B. G. (2007). Pemberdayaan Petani Sayuran: Kasus Petani Sayuran di Sulawesi Selatan. J. Penyuluhan, 3(1), 45-54.

Kusumawati, N. R. T. (2017). Peran Asosiasi Peternak Sapi Indonesia (ASPIN) Boyolali dalam Pemberdayaan Masyarakat. Publikasi Ilmiah, Fakultas K.

Mangowal, J. (2013). Pemberdayaan Masyarakat Petani dalam Meningkatkan Pengembangan Ekonomi Pedesaan di Desa Tumani Kecamatan Maesaan Kabupaten Minahasa Selatan. J. Governance, 5(1), 90-97.

Mario, S. (2017). Pemberdayaan Masyarakat Tani Melalui Gabungan Kelompok Tani di Desa Patanyamang Kacamatan Camba Kabupaten Maros. Predestinas, 10(1), 33-49.

Martati, I., Suminto, \& Syarifuddin, dan A. (2013). Model pengembangan penciptaan lapangan kerja melalui pengembangan ekonomi lokal pada Kecamatan 
Samarinda Ilir. J. Manajemen Dan Kewirausahaan, 15(2), 123-130. https://doi.org/10.9744/jmk.15.2.123-130

Nuryanti, S. (2011). Peran Kelompok Tani Dalam Penerapan Teknologi Pertanian Roles of Farmers ' Groups in Agricultural Technology Adoption. (70), 115-128.

Prasetyo, K. P. (2013). Persepsi Petani Terhadap Kemitraan Sayuran dengan Asosiasi Aspakusa Makmur Kabupaten Boyolali. Skripsi, Fakultas P.

Putranto, Y. A. (2012). Pengaruh moderasi informasi asimetri dan group cohesiveness terhadap hubungan partisipasi penganggaran dengan budgetary slack. J. Ecomonia, 8(2), 116-125.

Rifa, B. (2013). Efektivitas Pemberdayaan Usaha Mikro Kecil dan Menengah ( UMKM ) Krupuk Ikan dalam Program Pengembangan Labsite Pemberdayaan Masyarakat Desa Kedung Rejo Kecamatan Jabon Kabupaten Sidoarjo. J. Kebijakan Dan Manajemen Publik, 1(1), 130-136.

Saptana, Sunarsih, dan K. S. I. (2016). Mewujudkan keunggulan komparatif menjadi keunggulan kompetitif samelalui pengembangan kemitraan usaha hortikultur. Forum Penelitian Agro Ekonomi, 24(1), 61-76.

Setyo Nugroh, A., \& Rahayu, S. (2014). Peran Kelompok Tani Sido Makmur dalam Meningkatkan Kesejahteraan Anggota Kelompok Tani Sido Makmur Desa Ngaringan Kabupaten Grobogan. Jurnal Teknik PWK, 3(3), 506-518.

Sopyan, Y. (2014). Corporate social responsility (CRS) sebagai implementasi fikih sosial untuk pemberdayaan masyarakat. Ahkam, 14(1), 53-62.

Sugiarti, A., \& Ma'ruf, M. F. (2016). Strategi Pemberdayaan Masyarakat Petani Melalui Program Pengembangan Usaha Agribisnis Perdesaan (PUAP) di Kabupaten Ponorogo (Studi pada Pemberdayaan Gapoktan Margo Rejeki di Desa Sidoharjo Kecamatan Pulung Kabupaten Ponorogo). Universitas Negeri Surabaya, Surabaya, Skripsi, 1-11.

Sumarna, R. (2012). Pengaruh kemitraan terhadap penerapan teknologi dan pendapatan petani padi sehat di Kecamatan Kebon Pedes, Kabupaten Sukabumi. Institut Pertanian Bogor, Bogor, (Skripsi).

Taufik, M. (2012). Strategi pengembangan agribisnis sayuran di Sulawesi Selatan. J. Litbang, 31 (2), 43-50. 